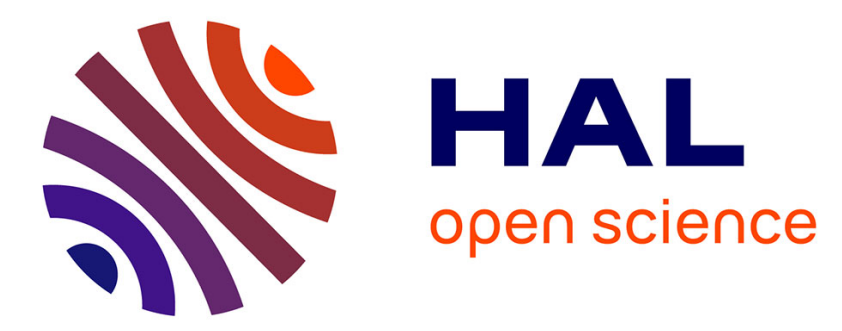

\title{
Efficacy and safety of autologous stem cell transplantation after induction therapy with lenalidomide, bortezomib, and dexamethasone
}

Robin Arcani, Geoffroy Venton, Julien Colle, Pierre Suchon, Vadim Ivanov, Cédric Mercier, Laure Farnault, Pauline Roche, Marina Lafage, Corinne Brunet, et al.

\section{To cite this version:}

Robin Arcani, Geoffroy Venton, Julien Colle, Pierre Suchon, Vadim Ivanov, et al.. Efficacy and safety of autologous stem cell transplantation after induction therapy with lenalidomide, bortezomib, and dexamethasone. European Journal of Haematology, 2019, 10.1111/ejh.13297 . hal-02267221

\section{HAL Id: hal-02267221 \\ https://hal-amu.archives-ouvertes.fr/hal-02267221}

Submitted on 18 Oct 2019

HAL is a multi-disciplinary open access archive for the deposit and dissemination of scientific research documents, whether they are published or not. The documents may come from teaching and research institutions in France or abroad, or from public or private research centers.
L'archive ouverte pluridisciplinaire HAL, est destinée au dépôt et à la diffusion de documents scientifiques de niveau recherche, publiés ou non, émanant des établissements d'enseignement et de recherche français ou étrangers, des laboratoires publics ou privés. 
Title: Efficacy and safety of autologous stem cell transplantation after induction therapy with Lenalidomide, Bortezomib and Dexamethasone

Authors: Robin Arcani a, Geoffroy Venton M.D., Ph.D., ${ }^{\mathrm{a}, \mathrm{b}, \mathrm{c}}$, Julien Colle M.D., ${ }^{\mathrm{a}, \mathrm{c}, \mathrm{c}}$, Pierre Suchon M.D. ${ }^{\text {de }}$, Vadim Ivanov M.D. ${ }^{\text {a }}$, Cédric Mercier M.D. ${ }^{\text {a,f }}$, Laure Farnault M.D. ${ }^{\text {a }}$, Pauline Roche $^{\text {a }}$, Marina Lafage M.D. ${ }^{\mathrm{g}}$, Corinne Brunet M.D. , Wakil Azouza P.D. ${ }^{\mathrm{i}}$, Bertrand Pourroy P.D. ${ }^{\mathrm{i}}$, Raphaëlle Fanciullino P.D. ${ }^{\mathrm{i}, \mathrm{j}}$, Regis Costello M.D., Ph.D. ${ }^{\mathrm{a}, \mathrm{b}, \mathrm{c}}$

${ }^{a}$ Hematology and Cellular Therapy Department, La Conception, University Hospital of Marseille, 147 Boulevard Baille, 13005 Marseille, France

b Aix-Marseille University, UMR1090 TAGC, 27 boulevard Jean Moulin, 13005 Marseille, France

${ }^{\mathrm{c}}$ INSERM, UMR1090 TAGC, Marseille, 27 boulevard Jean Moulin, 13005 Marseille, France

${ }^{\mathrm{d}}$ Hematology laboratory, La Timone, University Hospital of Marseille, 278 rue Saint-Pierre, 13005 Marseille, France

${ }^{\mathrm{e}}$ UMR 1062 NORT, INSERM, 27 boulevard Jean Moulin, 13005 Marseille, France

${ }^{\mathrm{f}}$ UMR-911 INSERM, Toxicokinetics and pharmacokinetics laboratory, pharmacological faculty, 27 boulevard Jean Moulin, 13005 Marseille, France

${ }^{\mathrm{g}}$ Genetic Department, La Timone, University Hospital of Marseille, 278 rue Saint-Pierre, 13005 Marseille, France

${ }^{\mathrm{h}}$ Hematology laboratory, La Conception, University Hospital of Marseille, 147 Boulevard Baille, 13005 Marseille, France

${ }^{\text {i }}$ Pharmacy Unit, La Conception University Hospital of Marseille, 147 Boulevard Baille, 13005 Marseille, France

${ }^{j}$ SMARTc Unit, Pharmacokinetics Laboratory, UMR_911 CRO2, 27 boulevard Jean Moulin, 13005 Marseille, France 


\title{
Corresponding Author
}

Mr Robin Arcani

Hematology and Cellular Therapy Department, La Conception, University Hospital of Marseille

147 Boulevard Baille, 13005 Marseille, France

E-mail: robin.arcani@ap-hm.fr

Phone number: +33670157164

Fax number: + 33491383989

Running title: Lenalidomide, Bortezomib, Dexamethasone

\begin{abstract}
Objectives: Recently, phase III trials assessed a new combination of Lenalidomide, Bortezomib and Dexamethasone (RVD) in induction therapy in transplantation-eligible Multiple Myeloma (MM) patients, before consolidation with RVD and Lenalidomide maintenance. We present a retrospective study evaluating this approach with patients from the real life.

Methods: We conducted a retrospective single-arm study to assess efficacy and safety of RVD combination in induction therapy before high-dose chemotherapy with Melphalan followed by autologous stem cell transplantation, and RVD consolidation followed by Lenalidomide maintenance, from February 2011 to May 2016.
\end{abstract}


Results: Forty patients were enrolled. The mean age at diagnosis was 56 years. Median progression-free survival was 45 months and median overall survival was 76 months. The only factor found associated with better PFS was a negative minimal residual disease $(\mathrm{p}<$ 0.01). Twenty-six (65\%) patients experimented adverse events: 8 patients $(20 \%)$ underwent 12 serious $\mathrm{AE}$ ( $\geq$ grade 3 ). Treatment discontinuation occurred in 2 patients $(5 \%)$ because of severe AE.

Conclusion: To our knowledge, this work provides the first evidence of the efficacy and the safety of RVD combination in patients treated in common practice.

\section{Keywords}

Lenalidomide; Bortezomib; Multiple myeloma; immunomodulatory therapy 


\section{Introduction}

Over the last 15 years, quality and duration of life for patients suffering from Multiple Myeloma (MM) have greatly improved thanks to the emergence of new therapeutic classes as the immunomodulatory drugs (thalidomide, lenalidomide, pomalidomide) and the proteasome inhibitors (bortezomib, carfilzomib, ixazomib) (1-9). High-dose chemotherapy following by autologous stem cell transplantation (ASCT) is recommended for all eligible MM patients. ASCT allows a better progression-free survival (PFS) and overall survival (OS) (10-14). High-dose melphalan (HDM) is mainly used as a conditioning regimen before ASCT (15-17). Recently, a combination of lenalidomide, bortezomib and dexamethasone (RVD) has been evaluated in induction, consolidation and maintenance therapy, in association or not with ASCT, showing a durable PFS and OS with this regimen $(18,19)$ and a longer PFS when RVD therapy is combined with ASCT (20). Moreover, a lower risk of drug-related serious neuropathy has been reported with the association of lenalidomide with bortezomib compared to the association of thalidomide and bortezomib (21-23). Nevertheless, this regimen has never been reported in real life practice. So, we led a retrospective study evaluating a transplantation-based approach with RVD combination as induction and consolidation and lenalidomide maintenance outside clinical trials, with patients from the real life. 


\section{Material and Methods}

We conducted a single-arm, retrospective study to assess efficacy and safety of RVD combination in transplantation-eligible patients. All the consecutive patients who received, in front-line, induction therapy with three (or four) 21-day cycles of RVD, which consisted of bortezomib (1.3 mg per square meter of body-surface area, administered subcutaneously on days $1,4,8$, and 11 ), lenalidomide (25 mg, administered orally on days 1 through 14 ), and dexamethasone (40 mg, administered orally on days 1, 4, 8 and 11) for MM (diagnosed on IMWG criteria) before intensification with HDM (200 mg per square meter of body-surface area) and ASCT, and 2 cycles of RVD in consolidation therapy followed by lenalidomide (10 $\mathrm{mg} / \mathrm{d}, 21$ days per 28-day cycle) maintenance (duration was at the practitioners' discretion), from February 2011 to May 2016, in a French tertiary care center, were included. Some patients could have received prior cycles of a combination of bortezomib and dexamethasone in case of renal insufficiency at diagnosis. Concomitantly, the patients received thromboprophylaxis with daily aspirin (100 mg) or low molecular weight heparin, prophylaxis against herpes zoster with valaciclovir (500 $\mathrm{mg}$ twice a day) and bisphosphonate therapy monthly during the first 12 months. Data were collected retrospectively consulting the medical and pharmaceutical files. The primary endpoint was PFS. Secondary endpoints included OS and safety. Treatment response and disease progression were assessed according to the International Uniform Response Criteria for Multiple Myeloma (24). Toxicity was graded using the Common Terminology Criteria for Adverse Events (CTCAE) Version 4.0. The minimal residual disease (MRD) evaluation was available for a part of patients. MRD was assessed using a 9 colors multiparametric flow cytometric immunophenotyping, using monoclonal antibodies against CD138-PC7, CD38-APC, CD19-ECD, CD56-PC5.5, CD200AA700, CD27-PB, CD45-KO, CyIgKappa-FITC and CyIgLambda-PE, all purchased from Beckman Coulter (Villepinte, France) in agreement with consensus guideline (25). Briefly, 
bone marrow (BM) aspirate, collected in tubes containing EDTA (ethylenediaminetetra-acetic acid) were washed in phosphate-buffered saline (PBS) and suspended in a PBS, $1.0 \%$ bovin serum albumin buffer adjusted to a final white cell concentration of $1-2 \times 10^{6} / \mathrm{mL}$. Next, 100 $\mu \mathrm{L}$ of washed $\mathrm{BM}$ aspirates were briefly vortexed before incubation with monoclonal antibodies at room temperature in the dark (membrane markers first, then intracytoplasmic markers with Perfix NC kit from Beckman Coulter). Acquisition of CD45 positive cells and subsequent analyses of markers were performed using a NAVIOS 3 lasers flow cytometer (Beckman Coulter, Miami, USA). Myeloma cells were identified according to their immunophenotype at diagnosis. Negative MRD interpretation was based upon a minimal record of 200.000 cellular events in order to reach a sensitivity level of $10^{-4}$ cells. The study was approved by the institutional review board of the Assistance Publique des Hôpitaux de Marseille and conducted in accordance with the Declaration of Helsinki. Quantitative variables were described using medians and range and categorical variables were described using numbers and percentages. Durations of follow-up, PFS and OS were estimated by means of the reverse Kaplan-Meier method, the PFS were compared between groups using stratified log rank tests. P-values $<0.05$ were considered significant. All analyses were performed with the XLStat 2018 software. 


\section{Results}

\section{Characteristics of the population}

Forty patients were enrolled in our analysis. Baseline demographic and disease characteristics are summarized in Table 1. Median age at diagnosis was 58 years (range: 32 - 68 years). There were 12 female (30\%) and 28 male (70\%) patients. A high-risk cytogenetic was defined as the presence of a chromosome $17 \mathrm{p}$ deletion or a $\mathrm{t}(4 ; 14)$ translocation. A fluorescent in situ hybridization (FISH) analysis was present in 26 patients $(65 \%): \mathrm{t}(4 ; 14)$ translocation was found in 4 patients $(15.4 \%)$ and 17 p deletion in 1 (3.8\%). Six patients received 2 prior cycles of bortezomib-dexamethasone before RVD induction due to an initial renal insufficiency. Twenty-six and 14 patients received 3 and 4 cycles of RVD induction, respectively. Ten patients were not under lenalidomide maintenance, 21 patients received lenalidomide maintenance for 1 year and 9 patients had lenalidomide maintenance until progressive disease.

\section{Safety}

Table 2 summarized the reported adverse events (AE). Eight patients (20\%) underwent 12 serious $\operatorname{AE}(\geq$ grade 3$)$ : neutropenia $(n=5)$, cutaneous $(n=2)$, thrombopenia $(n=2)$, neuropathy $(\mathrm{n}=2)$, asthenia $(\mathrm{n}=1)$. One patient $(2.5 \%)$ suffered from deep venous thrombosis. Peripheral sensorimotor neuropathy was reported in $21(52.5 \%)$ patients: grade 3 in 2 cases (5\%), grade 2 in 11 patients (27.5\%), grade 1 in 8 patients (20\%). Grade 3 infectious events consisted in recurrent respiratory tract infections in 2 patients $(5 \%)$. Treatment discontinuation occurred in 2 patients $(5 \%)$ because of severe AE. There was no treatment-related mortality.

\section{RVD efficacy}

After RVD induction and before ASCT, 30 patients (75\%) were in complete response (CR) or in very good partial response (VGPR). After ASCT and before RVD consolidation, 38 
patients $(95 \%)$ were in stringent CR (sCR), CR or VGPR. After RVD consolidation and before lenalidomide maintenance, 37 patients $(92.5 \%)$ were in VGPR or better. After all treatment sequences, 9 of the patients (22.5\%) achieved an MRD negativity (Table 3). The median follow-up from diagnosis was 47 months (range: 15 - 86 months). At data cutoff, 20 patients $(50 \%)$ did not experiment relapse, 9 patients were dead, and 1 patient was lost to follow-up. Median PFS was 45 months (range: 10 - 75 months) and median OS was 76 months (range: 14 - 86 months, Figure 1). High-risk cytogenetics, as International Staging System (ISS) disease stage at baseline, did not decrease significantly the PFS ( $p=0.542$ and $p$ $=0.848$, respectively, Figure 2). The patients who were in VGPR or better, at any moment of the evaluation, did not have a PFS significantly higher than those who were in partial response (PR), in stable disease (SD) or in progressive disease (PD) (Figure 3). PFS was not significantly influenced by the presence of lenalidomide maintenance (Figure 4). PFS was significantly longer in patients who achieved negative $\operatorname{MRD}(\mathrm{p}=0.008$, Figure 5).

\section{Strategy after relapse}

After the first relapse, 9 of 17 patients (53\%) were treated with an association of pomalidomide and dexamethasone. The 8 other patients received daratumumab $(\mathrm{n}=1)$, combination of bortezomib-doxorubicin-dexamethasone $(n=1)$, combination of bortezomibcyclophosphamide-dexamethasone $(n=2)$ and new cycles of RVD $(n=4)$. After the second relapse, 2 patients were treated with daratumumab, 3 received pomalidomide, 3 received bendamustine, 1 received combination of bortezomib-cyclophosphamide-dexamethasone and 1 was treated again by lenalidomide. 


\section{Discussion}

To our knowledge, our work presents the largest cohort in the literature evaluating efficacy and safety of RVD combination in front-line treatment of MM in transplantation-eligible patients, in real conditions of use, i.e. outside clinical trial. With a prolonged follow-up (median: 47 months), we found a long median PFS of 45 months, and a durable median OS of 76 months. This regimen was well tolerated with $20 \%$ of grade 3, or more, AE, and only 2 toxicity-related discontinuations of treatment. The results are consistent with those of the phase III trial of Attal et al (20), who obtained a median PFS of 50 months in the group treated with ASCT after RVD induction, which is more favorable compared to a thalidomidebortezomib-dexamethasone (TVD) regimen. In a meta-analysis evaluating TVD, Leiba et al (26) found a post-induction VGPR rate (or better) around $60 \%$, compared to $75 \%$ in our study. Moreover, the median PFS is higher with the RVD combination (45 months in our work) than with TVD (range: 18.3 - 33.1 months) (27-30). These results are similar to those found by Rosiñol et al in their integrated analysis of randomized clinical trials evaluating RVD or TVD (31): responses were deeper with RVD than TVD ( $\geq$ VGPR rate after induction with VRD vs VTD was $66.3 \%$ vs $51.2 \%$; $=0.00281$ ). Surprisingly, the usual risk factors of poor response, as cytogenetic abnormalities, VGPR or better response after induction, ISS disease stage, did not seem to influence the PFS. This could be due to the small size of our cohort. However, MRD negativity is statistically associated with a longer PFS ( $p<0.01)$. Even though these results can be due to the small size of our cohort, these findings confirm that the absence of MRD is an important treatment target in MM, particularly after ASCT $(18,20,32-$ 34). Safety was correct, with predictable and generally manageable toxicities. The main nonhematological AE of RVD was mild peripheral neuropathy in $47.5 \%$ of patients, and serious peripheral neuropathy ( $\geq$ grade 3 ) occurred in only $5 \%$ of patients. No serious neuropathy occurred during lenalidomide maintenance. Only one case of neuropathy and one severe 
neutropenia led to a lenalidomide discontinuation. Thus, neuropathy risk appeared to be significantly lower with lenalidomide than with thalidomide. The incidence of thalidomiderelated neuropathy (all grades) varies between 10 and 83\% (21-23,35-37). With TVD combination, the risk of peripheral neuropathy $\geq$ grade 3 is about 10 to $31 \%(26-29,38)$, in comparison to our $5 \%$ rate with RVD combination. This rate of peripheral neuropathy $\geq$ grade 3 related to RVD was similar to the rate found by Rosiñol et al comparing RVD and TVD (5\% versus $15.4 \%$ ) (31). In our cohort, only one thromboembolic event underwent, but in a patient who had discontinued his thromboprophylaxis, while no herpes zoster infection occurred. Surprisingly, we did not find secondary malignant event as in previous studies $(18,20)$. This could be due to the small effective of our cohort. But this confirms the low risk of second malignancy. The safety data are consistent with those collected in other studies with RVD combination (18-20). Overall, we found lower grade 3 or 4 AE with RVD (22.5\%) than reported with TVD (57\% in a recent meta-analysis) (26). Furthermore, a recent study showed superiority of RVD versus RD in patients non-candidates to ASCT (39). These results confirm the efficacy and the safety of this regimen, even in older patients thanks to a good profile of tolerance. So, we could apply the RVD regimen in patients non-candidates to ASCT, too. Even though our study suffers from its small size, it confirms the previous results about this strategy of MM treatment in transplantation-eligible patients. Moreover, we have led this study on patients from the real life, comparatively to the patients from controlledstudy, which they usually are younger, with fewer comorbidities and a stronger follow-up to avoid compliance issues than in real conditions of practice.

\section{Conclusion}

This work provides the first evidence of the efficacy and the safety of RVD combination as induction and consolidation after ASCT in patients treated in common practice. 


\section{References}

1. Andres M, Feller A, Arndt V, NICER Working Group. Trends of incidence, mortality, and survival of multiple myeloma in Switzerland between 1994 and 2013. Cancer Epidemiol. 2018 Apr;53:105-10.

2. Bergsagel PL. Where we were, where we are, where we are going: progress in multiple myeloma. Am Soc Clin Oncol Educ Book Am Soc Clin Oncol Meet. 2014;199-203.

3. Thorsteinsdottir S, Dickman PW, Landgren O, Blimark C, Hultcrantz M, Turesson I, et al. Dramatically improved survival in multiple myeloma patients in the recent decade: results from a Swedish population-based study. Haematologica. 2018 Mar 22;

4. Cowan AJ, Allen C, Barac A, Basaleem H, Bensenor I, Curado MP, et al. Global Burden of Multiple Myeloma: A Systematic Analysis for the Global Burden of Disease Study 2016. JAMA Oncol. 2018 May 16;

5. Facon T, Mary JY, Hulin C, Benboubker L, Attal M, Pegourie B, et al. Melphalan and prednisone plus thalidomide versus melphalan and prednisone alone or reduced-intensity autologous stem cell transplantation in elderly patients with multiple myeloma (IFM 9906): a randomised trial. Lancet Lond Engl. 2007 Oct 6;370(9594):1209-18.

6. Hulin C, Facon T, Rodon P, Pegourie B, Benboubker L, Doyen C, et al. Efficacy of melphalan and prednisone plus thalidomide in patients older than 75 years with newly diagnosed multiple myeloma: IFM 01/01 trial. J Clin Oncol Off J Am Soc Clin Oncol. 2009 Aug 1;27(22):3664-70.

7. Dimopoulos MA, Chen C, Spencer A, Niesvizky R, Attal M, Stadtmauer EA, et al. Long-term follow-up on overall survival from the MM-009 and MM-010 phase III trials 
of lenalidomide plus dexamethasone in patients with relapsed or refractory multiple myeloma. Leukemia. 2009 Nov;23(11):2147-52.

8. Weber DM, Chen C, Niesvizky R, Wang M, Belch A, Stadtmauer EA, et al. Lenalidomide plus dexamethasone for relapsed multiple myeloma in North America. $\mathrm{N}$ Engl J Med. 2007 Nov 22;357(21):2133-42.

9. Harousseau J-L, Attal M, Avet-Loiseau H, Marit G, Caillot D, Mohty M, et al. Bortezomib plus dexamethasone is superior to vincristine plus doxorubicin plus dexamethasone as induction treatment prior to autologous stem-cell transplantation in newly diagnosed multiple myeloma: results of the IFM 2005-01 phase III trial. J Clin Oncol Off J Am Soc Clin Oncol. 2010 Oct 20;28(30):4621-9.

10. Aggarwal M, Agrawal N, Yadav N, Verma P, Ahmed R, Mehta P, et al. Autologous stem cell transplantation in first remission is associated with better progression-free survival in multiple myeloma. Ann Hematol. 2018 May 21;

11. Moreau P, Attal M, Facon T. Frontline therapy of multiple myeloma. Blood. 2015 May $14 ; 125(20): 3076-84$.

12. Moreau P, San Miguel J, Sonneveld P, Mateos MV, Zamagni E, Avet-Loiseau H, et al. Multiple myeloma: ESMO Clinical Practice Guidelines for diagnosis, treatment and follow-up. Ann Oncol Off J Eur Soc Med Oncol. 2017 Jul 1;28(suppl_4):iv52-iv61.

13. Attal M, Harousseau JL, Stoppa AM, Sotto JJ, Fuzibet JG, Rossi JF, et al. A prospective, randomized trial of autologous bone marrow transplantation and chemotherapy in multiple myeloma. Intergroupe Français du Myélome. N Engl J Med. 1996 Jul $11 ; 335(2): 91-7$. 
14. Child JA, Morgan GJ, Davies FE, Owen RG, Bell SE, Hawkins K, et al. High-dose chemotherapy with hematopoietic stem-cell rescue for multiple myeloma. N Engl J Med. 2003 May 8;348(19):1875-83.

15. Moreau P, Facon T, Attal M, Hulin C, Michallet M, Maloisel F, et al. Comparison of $200 \mathrm{mg} / \mathrm{m}(2)$ melphalan and 8 Gy total body irradiation plus $140 \mathrm{mg} / \mathrm{m}(2)$ melphalan as conditioning regimens for peripheral blood stem cell transplantation in patients with newly diagnosed multiple myeloma: final analysis of the Intergroupe Francophone du Myélome 9502 randomized trial. Blood. 2002 Feb 1;99(3):731-5.

16. Barlogie B, Hall R, Zander A, Dicke K, Alexanian R. High-dose melphalan with autologous bone marrow transplantation for multiple myeloma. Blood. 1986 May;67(5):1298-301.

17. McElwain TJ, Gore ME, Meldrum M, Viner C, Judson IR, Malpas JS. VAMP followed by high dose melphalan and autologous bone marrow transplantation for multiple myeloma. Bone Marrow Transplant. 1989 Dec;4 Suppl 4:109-12.

18. Roussel M, Lauwers-Cances V, Robillard N, Hulin C, Leleu X, Benboubker L, et al. Front-line transplantation program with lenalidomide, bortezomib, and dexamethasone combination as induction and consolidation followed by lenalidomide maintenance in patients with multiple myeloma: a phase II study by the Intergroupe Francophone du Myélome. J Clin Oncol Off J Am Soc Clin Oncol. 2014 Sep 1;32(25):2712-7.

19. O’Donnell EK, Laubach JP, Yee AJ, Chen T, Huff CA, Basile FG, et al. A phase 2 study of modified lenalidomide, bortezomib and dexamethasone in transplant-ineligible multiple myeloma. Br J Haematol. 2018 May 8; 
20. Attal M, Lauwers-Cances V, Hulin C, Leleu X, Caillot D, Escoffre M, et al. Lenalidomide, Bortezomib, and Dexamethasone with Transplantation for Myeloma. N Engl J Med. 2017 06;376(14):1311-20.

21. Koeppen S. Treatment of multiple myeloma: thalidomide-, bortezomib-, and lenalidomide-induced peripheral neuropathy. Oncol Res Treat. 2014;37(9):506-13.

22. Aguiar PM, de Mendonça Lima T, Colleoni GWB, Storpirtis S. Efficacy and safety of bortezomib, thalidomide, and lenalidomide in multiple myeloma: An overview of systematic reviews with meta-analyses. Crit Rev Oncol Hematol. 2017 May;113:195212.

23. Luo J, Gagne JJ, Landon J, Avorn J, Kesselheim AS. Comparative effectiveness and safety of thalidomide and lenalidomide in patients with multiple myeloma in the United States of America: A population-based cohort study. Eur J Cancer Oxf Engl 1990. $2017 ; 70: 22-33$.

24. Durie BGM, Harousseau J-L, Miguel JS, Bladé J, Barlogie B, Anderson K, et al. International uniform response criteria for multiple myeloma. Leukemia. 2006 Sep;20(9):1467-73.

25. Stetler-Stevenson M, Paiva B, Stoolman L, Lin P, Jorgensen JL, Orfao A, et al. Consensus guidelines for myeloma minimal residual disease sample staining and data acquisition. Cytometry B Clin Cytom. 2016 Jan;90(1):26-30.

26. Leiba M, Kedmi M, Duek A, Freidman T, Weiss M, Leiba R, et al. Bortezomibcyclophosphamide-dexamethasone (VCD) versus bortezomib-thalidomidedexamethasone (VTD) -based regimens as induction therapies in newly diagnosed 
transplant eligible patients with multiple myeloma: a meta-analysis. Br J Haematol. 2014 Sep;166(5):702-10.

27. Moreau P, Avet-Loiseau H, Facon T, Attal M, Tiab M, Hulin C, et al. Bortezomib plus dexamethasone versus reduced-dose bortezomib, thalidomide plus dexamethasone as induction treatment before autologous stem cell transplantation in newly diagnosed multiple myeloma. Blood. 2011 Nov 24;118(22):5752-5758; quiz 5982.

28. Garderet L, Iacobelli S, Moreau P, Dib M, Lafon I, Niederwieser D, et al. Superiority of the triple combination of bortezomib-thalidomide-dexamethasone over the dual combination of thalidomide-dexamethasone in patients with multiple myeloma progressing or relapsing after autologous transplantation: the MMVAR/IFM 2005-04 Randomized Phase III Trial from the Chronic Leukemia Working Party of the European Group for Blood and Marrow Transplantation. J Clin Oncol Off J Am Soc Clin Oncol. 2012 Jul 10;30(20):2475-82.

29. Wu S, Zheng C, Chen S, Cai X, Shi Y, Lin B, et al. Subcutaneous Administration of Bortezomib in Combination with Thalidomide and Dexamethasone for Treatment of Newly Diagnosed Multiple Myeloma Patients. BioMed Res Int. 2015;2015:927105.

30. Rosiñol L, Oriol A, Teruel AI, Hernández D, López-Jiménez J, de la Rubia J, et al. Superiority of bortezomib, thalidomide, and dexamethasone (VTD) as induction pretransplantation therapy in multiple myeloma: a randomized phase 3 PETHEMA/GEM study. Blood. 2012 Aug 23;120(8):1589-96.

31. Dachs LR, Hebraud B, Oriol A, Colin A-L, Rios R, Hulin C, et al. Integrated Analysis of Randomized Controlled Trials Evaluating Bortezomib + Lenalidomide + Dexamethasone or Bortezomib + Thalidomide + Dexamethasone Induction in 
Transplant-Eligible Newly Diagnosed Multiple Myeloma. Blood. 2018 Nov 21;132(Suppl 1):3245.

32. Paiva B, Vidriales M-B, Cerveró J, Mateo G, Pérez JJ, Montalbán MA, et al. Multiparameter flow cytometric remission is the most relevant prognostic factor for multiple myeloma patients who undergo autologous stem cell transplantation. Blood. 2008 Nov 15;112(10):4017-23.

33. Rawstron AC, Child JA, de Tute RM, Davies FE, Gregory WM, Bell SE, et al. Minimal residual disease assessed by multiparameter flow cytometry in multiple myeloma: impact on outcome in the Medical Research Council Myeloma IX Study. J Clin Oncol Off J Am Soc Clin Oncol. 2013 Jul 10;31(20):2540-7.

34. Martinez-Lopez J, Lahuerta JJ, Pepin F, González M, Barrio S, Ayala R, et al. Prognostic value of deep sequencing method for minimal residual disease detection in multiple myeloma. Blood. 2014 May 15;123(20):3073-9.

35. Plasmati R, Pastorelli F, Cavo M, Petracci E, Zamagni E, Tosi P, et al. Neuropathy in multiple myeloma treated with thalidomide: a prospective study. Neurology. 2007 Aug 7;69(6):573-81.

36. Cavaletti G, Beronio A, Reni L, Ghiglione E, Schenone A, Briani C, et al. Thalidomide sensory neurotoxicity: a clinical and neurophysiologic study. Neurology. 2004 Jun 22;62(12):2291-3.

37. Glasmacher A, Hahn C, Hoffmann F, Naumann R, Goldschmidt H, von Lilienfeld-Toal M, et al. A systematic review of phase-II trials of thalidomide monotherapy in patients with relapsed or refractory multiple myeloma. Br J Haematol. 2006 Mar;132(5):584-93. 
38. Cavo M, Tacchetti P, Patriarca F, Petrucci MT, Pantani L, Galli M, et al. Bortezomib with thalidomide plus dexamethasone compared with thalidomide plus dexamethasone as induction therapy before, and consolidation therapy after, double autologous stem-cell transplantation in newly diagnosed multiple myeloma: a randomised phase 3 study. Lancet Lond Engl. 2010 Dec 18;376(9758):2075-85.

39. Durie BGM, Hoering A, Abidi MH, Rajkumar SV, Epstein J, Kahanic SP, et al. Bortezomib with lenalidomide and dexamethasone versus lenalidomide and dexamethasone alone in patients with newly diagnosed myeloma without intent for immediate autologous stem-cell transplant (SWOG S0777): a randomised, open-label, phase 3 trial. Lancet Lond Engl. 2017 Feb 04;389(10068):519-27. 

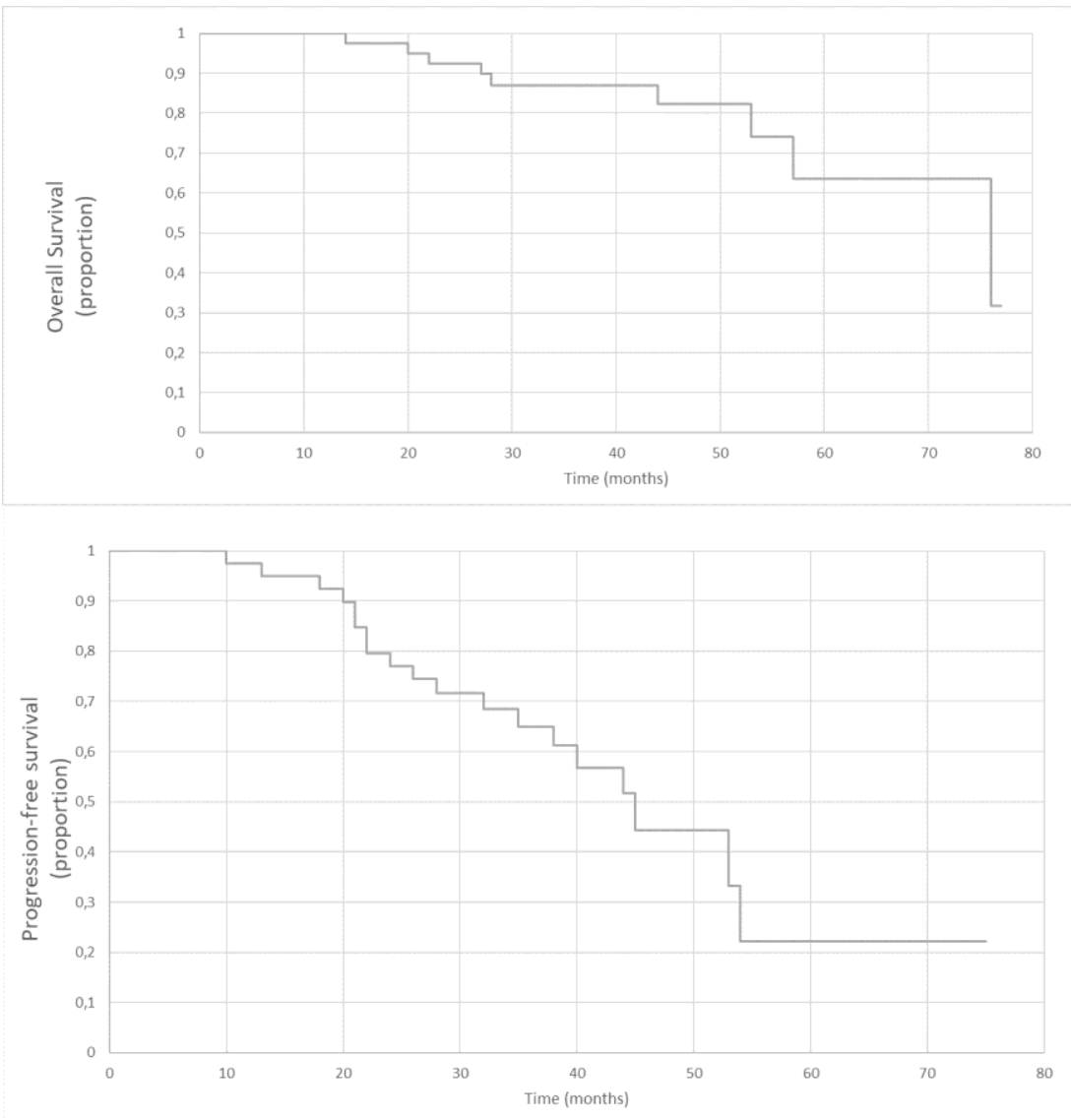

Figure 1

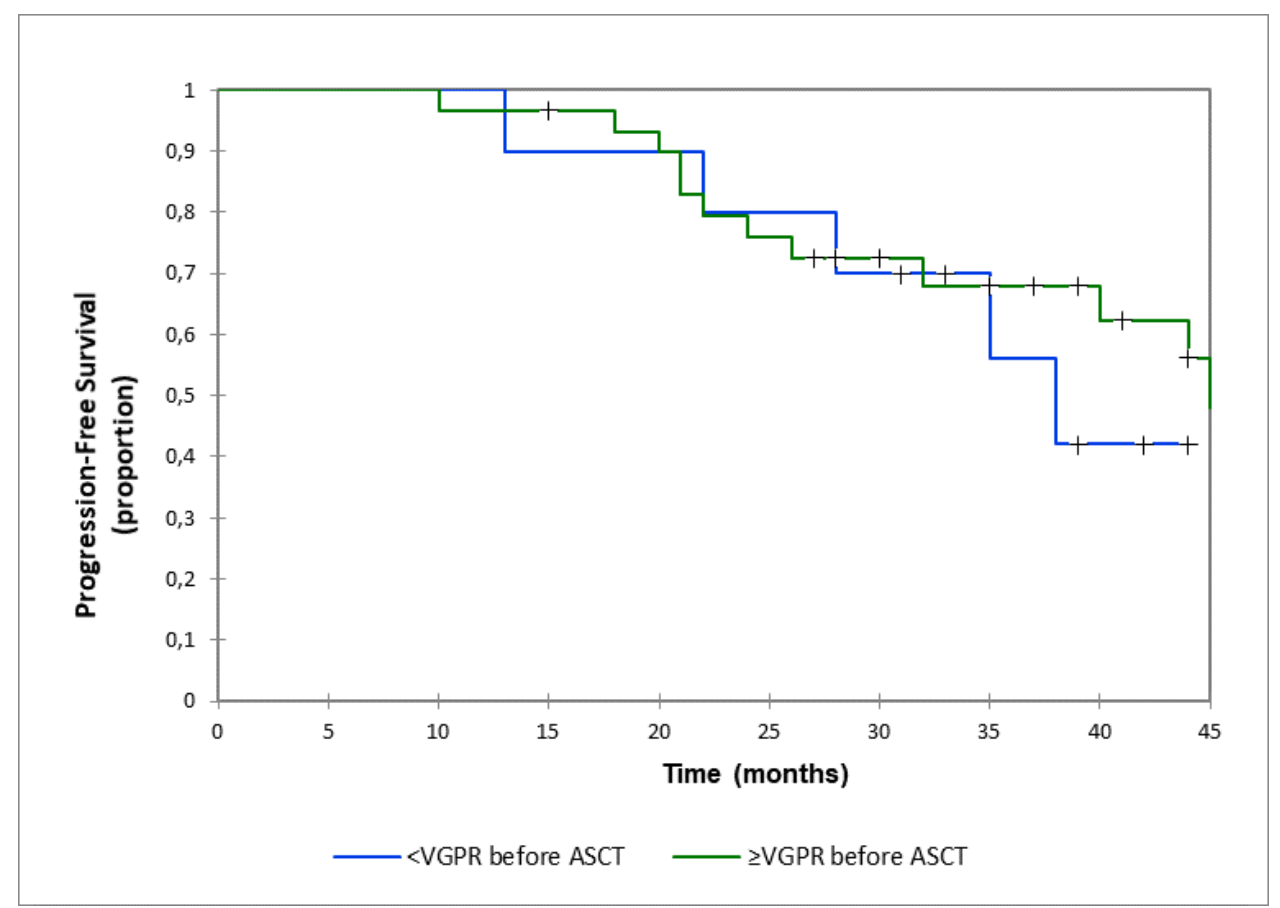


Figure 3

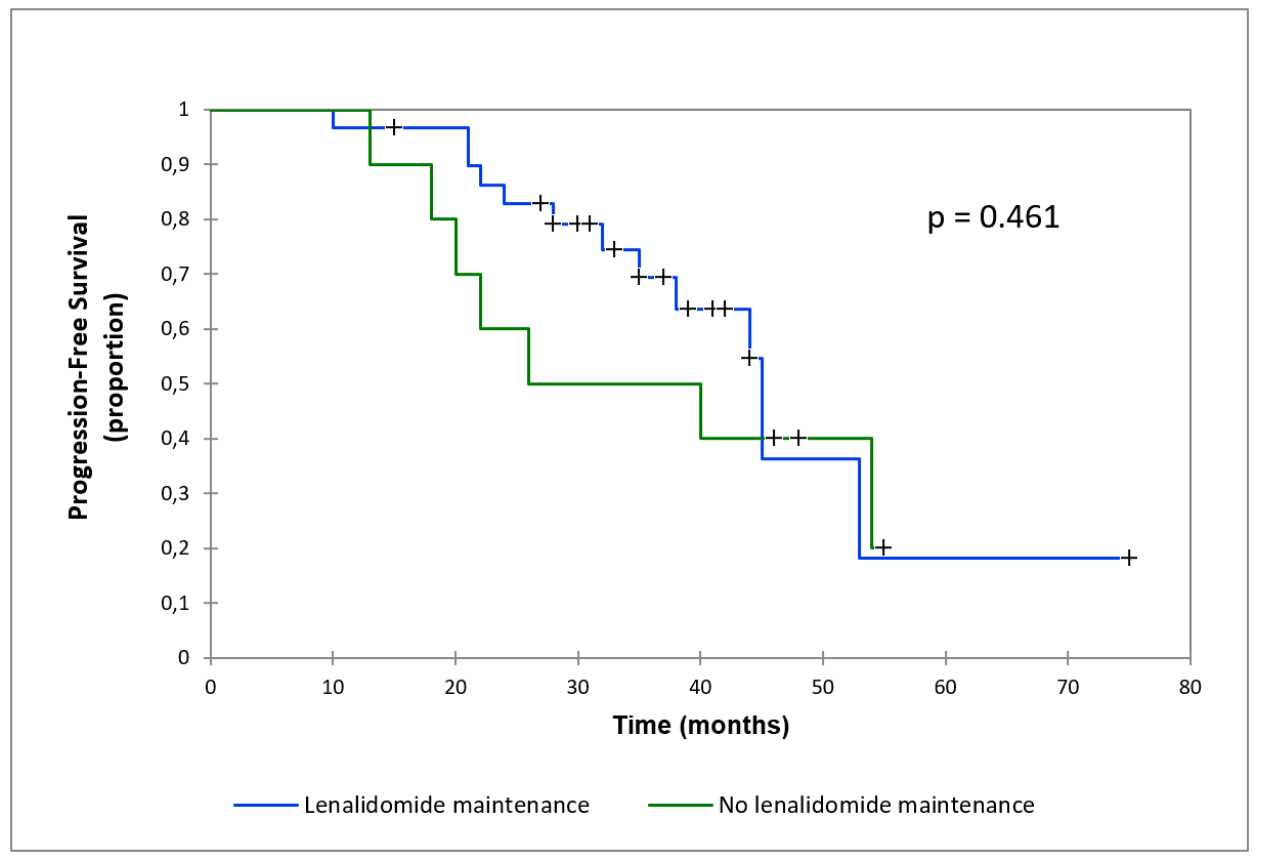

Figure 4

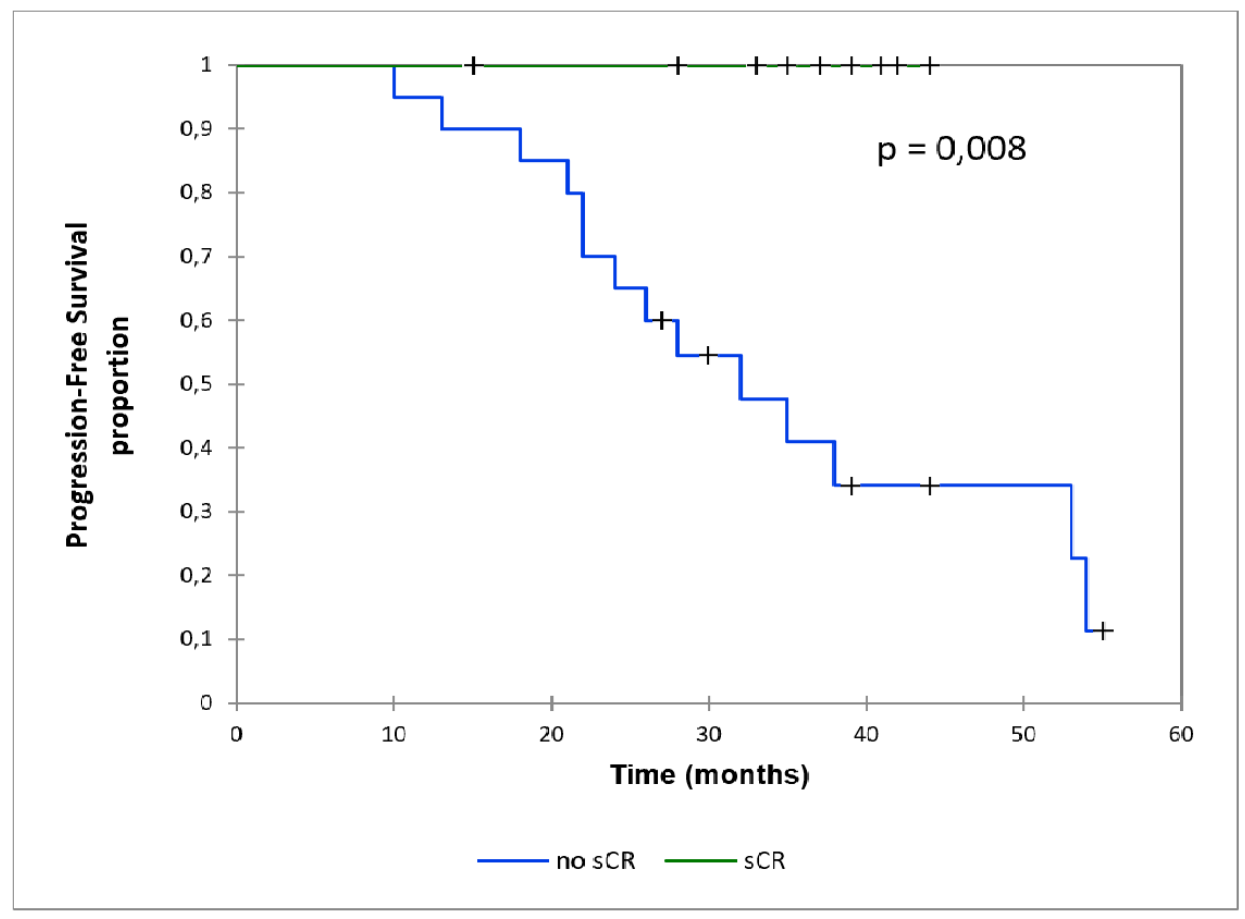

Figure 


\begin{tabular}{cc}
\hline Characteristics & \\
\hline Age (median, [range]) & $58[32-68]$ \\
Sex (n, \%) & $28(70)$ \\
Male & $12(30)$ \\
Female & $19(47.5)$ \\
IgG IgA & $11(27.5)$ \\
Type of myeloma (n) & $9(22.5)$ \\
Light chain kappa & $0(0)$ \\
Light chain lambda & $1(2.5)$ \\
Non-secretory & $13(32.5)$ \\
\%) & $11(27.5)$ \\
II & $13(32.5)$ \\
III & $3(7.5)$ \\
Unknown & \\
\hline International Staging System disease stage (n, & $4(15.4)$ \\
FISH analysis (n, \%) & $1(3.8)$ \\
17:14) translocation deletion & $14(35)$ \\
Unknown & $30[3-94]$ \\
\hline Bone marrow plasma cells, \% (median, [range]) & $78[49-444]$ \\
\hline Creatinine, $\mu$ mol/L (median, [range]) &
\end{tabular}

Table 1: Baseline characteristic of patients and disease 


\begin{tabular}{ccccc}
\hline Adverse Events (AE) & $\begin{array}{c}\text { Any grade } \\
\text { (at any time) }\end{array}$ & $\begin{array}{c}\text { Grade 3 or higher } \\
\text { (at any time) }\end{array}$ & $\begin{array}{c}\text { Grade 3 or higher } \\
\text { (VDR Induction } \\
\text { or Consolidation) }\end{array}$ & $\begin{array}{c}\text { Grade 3 or } \\
\text { higher } \\
\text { (Lenalidomide } \\
\text { Maintenance) } \\
\text { n= 30 }\end{array}$ \\
\hline Any AE & $26(65 \%)$ & $9(22.5 \%)$ & $3(7.5 \%)$ & $6(20 \%)$ \\
\hline Hematological disorder & $7(17.5 \%)$ & $2(5 \%)$ & 0 & $2(6.67 \%)$ \\
Thrombopenia & $2(5 \%)$ & 0 & 0 & 0 \\
Anemia & $10(25 \%)$ & $5(12.5 \%)$ & $4(10 \%)$ & $1(3.33 \%)$ \\
Neutropenia & $21(52.5 \%)$ & $2(5 \%)$ & $2(5 \%)$ & 0 \\
\hline Peripheral neuropathy & $1(2.5 \%)$ & $1(2.5 \%)$ & 0 & 0 \\
\hline Asthenia & $8(20 \%)$ & 0 & 0 & 0 \\
\hline Gastrointestinal disorders & $2(5 \%)$ & 0 & 0 & 0 \\
Stomatitis & $1(2.5 \%)$ & 0 & 0 & 0 \\
Anorexia & $1(2.5 \%)$ & 0 & 0 & 0 \\
Gingival hemorrhage & $2(5 \%)$ & 0 & 0 & 0 \\
Nausea & $2(5 \%)$ & 0 & 0 & 0 \\
\hline Constipation & $1(2.5 \%)$ & 0 & 0 & 0 \\
\hline Cytolytic hepatitis & $1(2.5 \%)$ & 0 & 0 & $2(6.67 \%)$ \\
\hline Thromboembolism & $2(5 \%)$ & 0 & 0 & 0 \\
\hline Infections & $5(12.5 \%)$ & $2(5 \%)$ & & 0 \\
\hline Cutaneous & & & 0 \\
\hline
\end{tabular}

Table 2: Treatment-related adverse events 


\begin{tabular}{cccc}
\hline Response $(\mathrm{n}, \%)$ & $\begin{array}{c}\text { After induction } \\
\text { therapy }\end{array}$ & After ASCT & $\begin{array}{c}\text { After consolidation } \\
\text { therapy }\end{array}$ \\
\hline SCR & $0(0)$ & $1(2.5)$ & $9(22.5)$ \\
CR & $9(22.5)$ & $12(30)$ & $11(27.5)$ \\
VGPR & $21(52.5)$ & $25(62.5)$ & $17(42.5)$ \\
PR & $10(25)$ & $2(5)$ & $3(7.5)$ \\
\hline
\end{tabular}

Table 3: Response rate after different phases of treatment

ASCT: autologous stem cell transplantation; sCR: stringent complete response; CR: complete response; VGPR: very good partial response; PR: partial response 